\title{
Late marrow recurrences in childhood acute lymphoblastic leukaemia
}

\author{
JUDITH M CHESSELLS, F BREATNACH
}

\begin{abstract}
Thirty children with acute lymphoblastic leukaemia had a recurrence in the bone marrow after treatment was stopped electively. A second haematological remission was achieved in $27(90 \%)$, and the median duration of remission was shortest (six months) in those relapsing within six months of stopping treatment. Four of six children relapsing over one year after stopping treatment remained in second haematological remission. Leukaemic infiltration of the central nervous system developed in four patients remaining in marrow remission.

It is concluded that conventional chemotherapy is unlikely to be effective in children with acute lymphoblastic leukaemia who relapse soon after stopping treatment, that "reprophylaxis" of the central nervous system probably with long-term intrathecal chemotherapy is essential, and that some patients relapsing after prolonged unmaintained remission may achieve long-term leukaemia-free survival.
\end{abstract}

\section{Introduction}

Children with acute lymphoblastic leukaemia who experience bone-marrow recurrence during treatment have a uniformly poor prognosis. ${ }^{2}$ The outlook for patients relapsing after treatment has been electively stopped remains uncertain, but long-term survival appears possible in some patients. ${ }^{3}$ We report here our experience in managing a group of such patients with late relapse and discuss implications for future treatment.

\footnotetext{
Department of Haematology, Hospital for Sick Children, Great Ormond Street, London WCiN 3JH

JUDITH M CHESSELLS, MD, FRCP, consultant clinical haematologist F BREATNACH, MB, MRCP, leukaemia research fellow
}

\section{Patients and methods}

Altogether 136 children with acute lymphoblastic leukaemia diagnosed between 1971 and 1976 who attended the leukaemia clinic at this hospital had treatment electively stopped after two to three years of complete remission. Thirty-four of these children subsequently had a bone-marrow or combined marrow and testicular recurrence. We report here on 30 of the children who relapsed before March 1979 and were followed up for a minimum of two years.

All patients had initially been treated according to protocols designed by or being piloted for the Medical Research Council Working Party on Leukaemia in Childhood ${ }^{4-6}$ and comprising induction of remission with prednisolone, vincristine, and colaspase ( $\mathrm{L}$-asparaginase). Some patients received additional agents during induction and consolidation: cytarabine (cytosine arabinoside), cyclophosphamide, and doxorubicin. All patients had received "prophylactic treatment" to the central nervous system consisting of cranial irradiation (2400 rads) with spinal irradiation or intrathecal methotrexate or both. Continuing (maintenance) chemotherapy varied with protocol but comprised in most instances mercaptopurine, methotrexate, prednisolone, and vincristine with the addition of cytarabine and cyclophosphamide in some cases. Most patients were entered in protocols in which duration of chemotherapy was randomised and were thus treated for either two or three years.

Treatment after relapse was started with prednisolone and vincristine followed by consolidation chemotherapy with two courses of COAP (cyclophosphamide, cytarabine, vincristine, and prednisolone) and a course of colaspase with one injection of adriamycin; five patients instead received daunorubicin and colaspase during consolidation. Treatment continued with mercaptopurine, methotrexate, prednisolone, and vincristine according to the UKALL II protocol. ${ }^{4}$ Boys with concurrent testicular disease received irradiation to both testicles: four received 2400 rads in 12 fractions and two 1500 rads in six fractions. Originally central nervous system prophylaxis after relapse comprised a course of five intrathecal methotrexate injections given during induction and consolidation. All patients relapsing after January 1979 received in addition regular intrathecal methotrexate at six-weekly intervals.

\section{Results}

The patients comprised 14 girls and 16 boys, of whom six had concurrent testicular disease. No patient had disease of the central nervous system at the time of relapse. Nine patients had had a 
leucocyte count exceeding $20 \times 10^{9} / 1$ at diagnosis and six a count exceeding $50 \times 10^{9} / 1$. Immunological classification of blast cells at diagnosis had been performed in 18 patients $^{7}$ : one had $\mathrm{T}$, three null, and the rest common acute lymphoblastic leukaemia.

\section{TIME OF FIRST RELAPSE}

The first relapse occurred in this series between two and 41 months after chemotherapy was stopped. The patients (table) were divided into four groups according to the time elapsing between stopping treatment and relapse. Twenty-four patients $\left(80^{\prime \prime \prime}\right)$ relapsed within one year of stopping treatment (groups 1 and 2) and most of the rest within the second year.

Outcome after marrow relapse related to time after stopping chemotherapy

\begin{tabular}{lcccc}
\hline & $\begin{array}{c}\text { Group 1 } \\
\text { (early: } \\
6 \text { months) }\end{array}$ & $\begin{array}{c}\text { Group 2 } \\
\text { (intermediate: } \\
6-12 \text { months) }\end{array}$ & $\begin{array}{c}\text { Group 3 } \\
\text { (late: } \\
\text { 13-24 months) }\end{array}$ & $\begin{array}{c}\text { Group 4 } \\
\text { (very late: } \\
\text { 24 months) }\end{array}$ \\
\hline $\begin{array}{l}\text { No remission } \\
\text { Second recurrence } \\
\text { in marrow }\end{array}$ & 3 & 4 & $2^{*}$ & \\
$\begin{array}{l}\text { Second recurrence } \\
\text { in central nervous } \\
\text { system }\end{array}$ & 11 & 3 & 1 & 2 \\
$\begin{array}{l}\text { Death in remission } \\
\text { Continued in second } \\
\text { complete remission }\end{array}$ & 1 & $1+$ & 1 & 2 \\
\hline Total & 16 & 8 & 4 & \\
\hline
\end{tabular}

*One defaulted from clinic. + Second primary tumour.

\section{RESPONSE TO REINDUCTION}

A second remission was achieved in 27 patients $\left(90^{\circ}\right)$, in 26 within six weeks of chemotherapy being restarted. The three failures of induction all occurred among the 16 children in group 1: one child died from septicaemia, one from metabolic complications, and one six months after relapse without achieving a second remission.

\section{DURATION OF SECOND REMISSION (figure)}

A second marrow recurrence soon supervened in 11 of the 13 patients in group 1. One child, who had developed portal fibrosis, died in remission from septicaemia due to Pseudomonas aeruginosa.

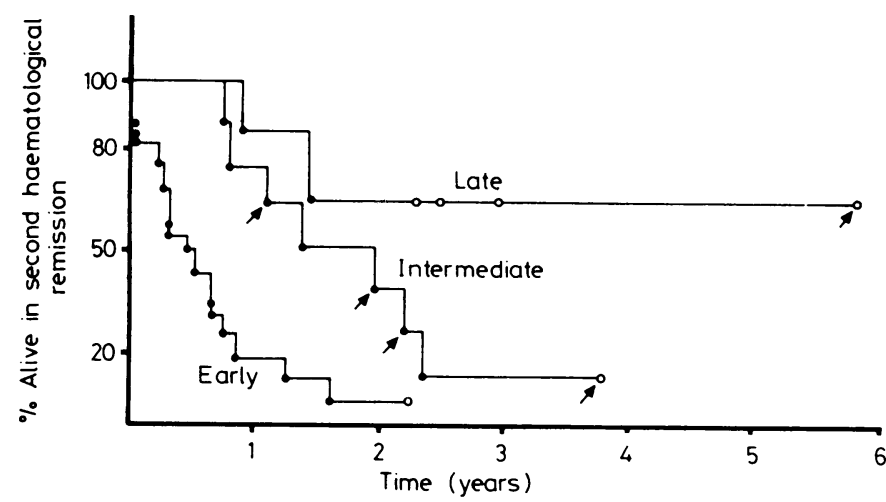

Duration of second haematological remission in patients relapsing early (group 1), at an intermediate time (group 2), and late (groups 3 and 4) after stopping treatment. Arrows denote four patients in whom second remission ended in recurrence in the central nervous system and one patient who developed a spinal tumour.

The only surviving child in the group received a bone-marrow transplant from an HLA-identical sibling during second remission and remained well 26 months later. No patient in this "early" group developed leukaemic cells in the central nervous system.
Leukaemic cells developed in the central nervous system in several of the patients in group 2. Four of the eight patients had a second marrow recurrence without prior central nervous system recurrence, but in two patients, who both received only five intrathecal methotrexate injections, central nervous system recurrence preceded marrow recurrence. A seventh child, who received five intrathecal methotrexate injections, remained in haematological remission at 48 months, central nervous system and testicular infiltration having been diagnosed at 37 months. The eighth child in group 2 was receiving regular intrathecal methotrexate when, after seven and a half months in second remission, she developed signs of spinal-cord compression, which was associated with the finding of an intramedullary tumour on myelography. A temporary remission was achieved with radiotherapy, but she died from recurrence of the tumour two years after her first relapse; the tumour proved to be a cystic astrocytoma of the spinal cord.

Two of the four patients in group 3 (in whom relapses occurred during the second year off treatment) had a second marrow recurrence, one of them after defaulting from the clinic and stopping treatment. A third patient, who did not receive long-term intrathecal methotrexate, subsequently developed central nervous system recurrence after stopping treatment for the second time and remained well in her second haematological remission after craniospinal irradiation. The fourth child in the group remained well at 30 months in second remission, receiving regular intrathecal methotrexate. The two patients who relapsed after two years off treatment (group 4) remained well at 29 and 39 months; the latter had stopped his second course of chemotherapy seven months previously.

\section{STOPPING TREATMENT A SECOND TIME}

There was no uniform approach regarding the duration of the second course of chemotherapy but treatment was stopped in two patients. One girl in group 3, who received only five intrathecal methotrexate injections, was treated for five years and had a central nervous system recurrence within six months after stopping treatment for a second time. One boy in group 4 stopped treatment second time after two and a half years in complete remission; he had received intrathecal methotrexate during maintenance treatment and was given a second course of cranial irradiation.

\section{Discussion}

Although the prognosis for children who relapse after stopping treatment is better than for those relapsing during treatment, ${ }^{1}$ few will apparently achieve long-term disease-free survival. Like others, ${ }^{3}$ we found that relapse within six months after treatment is stopped carries a particularly poor prognosis: the median duration of second haematological remission for such children in this series was only six months. By contrast, four out of six patients who relapsed after more than one year without treatment remained in second haematological remission, thus confirming an early report that patients relapsing after prolonged unmaintained remission have some chance of prolonged survival. ${ }^{*}$

As might be expected by extrapolation from experience in newly diagnosed acute lymphoblastic leukaemia," more prolonged haematological remission was associated with an increased risk of leukaemic infiltration of the central nervous system. This was also found in another group of patients, ${ }^{10}$ when prophylactic treatment of the central nervous system was not routinely used. In the present study a course of five intrathecal methotrexate injections during induction of second remission and subsequent consolidation was unsuccessful in preventing leukaemic infiltration of the central nervous system. Subsequently we adopted the use of regular intrathecal methotrexate, after which no patient in this study had a central nervous system recurrence. The need for further prophylactic cranial irradiation in such patients remains unknown; the possible benefit must be weighed against the risk of methotrexateradiation toxicity.

In conclusion, it appears that the outlook for children 
relapsing after stopping treatment for acute lymphoblastic leukaemia depends on the time that has elapsed since they stopped treatment. In children relapsing during the first six months or so there is a high risk of early marrow recurrence and they should be considered for marrow transplantation during second remission if there is a suitable donor. In patients relapsing later prolonged haematological remission is possible. We are presently studying the effect of more intensive induction and consolidation treatment in both groups of patients; whether this approach will increase the proportion of long-term survivors remains to be seen.

Further central nervous system prophylaxis is imperative for all children who have a bone-marrow recurrence after stopping treatment; intrathecal chemotherapy is the most appropriate method because it is less likely to compromise the delivery of systemic chemotherapy and avoids the undesirable effects of further cranial irradiation. The role of further "delayed" irradiation in long-term survivors remains unclear and will perhaps be elucidated by extrapolation from results of trials evaluating the necessity for routine irradiation in all newly diagnosed cases of acute lymphoblastic leukaemia.

We thank the Medical Research Council and the Leukaemia Research Fund for support, Mrs Carolyn Nelson for data collection, and Mrs Jean Bridger for secretarial help.

\section{References}

${ }^{1}$ Cornbleet MA, Chessells JM. Bone-marrow relapse in acute lymphoblastic leukaemia in childhood. Br Med F 1978;ii:104-6.

${ }^{2}$ Ekert H, Ellis WM, Waters KD. Poor outlook for childhood acute lymphoblastic leukaemia with relapse. Med F Aust 1979;66:224-6.

${ }^{3}$ Rivera G. Recurrent childhood lymphocytic leukemia : out come of marrow relapses after cessation of therapy. In: Neth R, Gallo RC, Graf T, Mannweiler K, Winkler K. Modern trends in leukemia IV. Berlin: Springer Verlag (in press).

${ }^{4}$ Medical Research Council. Analysis of treatment in childhood leukaemia. II. Timing and the toxicity of combined 6-mercaptopurine and methotrexate maintenance therapy. Sr $\tilde{J}$ Haematol 1976;33:179-88.

${ }^{5}$ Medical Research Council. Anaiysis of treatment in childhood leukaemia. $\mathrm{V}$. Advantage of reducing chemotherapy during and immediately after cranial irradiation. Br $\mathcal{F}$ Cancer $1977 ; 36: 625-33$.

${ }^{6}$ Rapson NT, Cornbleet MA, Chessells JM, Bennett T, Hardisty RM. Immunosuppression and serious infections in children with acute lymphoblastic leukaemia: a comparison of three chemotherapy regimes. Br.F Haematcl 1980;45:41-52.

7 Chessells JM, Hardisty RM, Rapson NT, Greaves M. Acute lymphoblastic leukaemia in children: classification and prognosis. Lancet 1977 ;ii:1307-9

${ }^{8}$ Leventhal BG, Levine AS, Graw RG, Simon R, Freirich EJ, Henderson ES. Long term second remissions in acute lymphatic leukemia. Cancer $1975 ; 35: 1136-40$

${ }^{9}$ Hardisty RM, Norman PM. Meningeal leukaemia. Arch Dis Child 1967;42:441-7.

1" Rivera G, Aur RJA, Dahl GV, et al. Second cessation of therapy in childhood lymphocytic leukemia. Blood 1979;53:1114-20.

(Accepted 25. Yune 1981)

\title{
Oestrogen receptor proteins in malignant and fetal pancreas
}

\author{
BRIAN GREENWAY，M J IQBAL，P J JOHNSON， ROGER WILLIAMS
}

\begin{abstract}
High levels of high-affinity oestrogen binding were detected in cytosolic and nuclear fractions of tumour tissue from six patients with pancreatic carcinoma. Similar binding was found in fetal but not in normal adult pancreas, making derepression of fetal genes a possibility. Specific androgen binding was not detectable.

These findings suggest that anti-oestrogen treatment may offer a new approach to the treatment of pancreatic carcinoma.
\end{abstract}

\section{Introduction}

High levels of cytosolic oestrogen and androgen receptor binding have been detected in breast carcinoma tissue. ${ }^{2}$ High cytosolic oestrogen receptor binding may be used to predict an increased possibility of clinical response to anti-oestrogen treatment or hormone ablation. About $40^{\prime \prime}$ of patients with breast carcinoma do not respond to treatment, and this has been attributed to failure of the oestrogen receptor complex to bind to the nucleus. Recent evidence suggests that the detection of nuclear as well as cytosolic binding may give a better prediction of response. ${ }^{3}$ Cytosolic oestrogen receptors have been reported in several other human tumours ${ }^{4-7}$ including two cases of

Liver Unit, King's College Hospital and Medical School, London SE5 8R X

BRIAN GREENWAY, MRCP, FRCS, clinical research fellow

M J IQBAL, PHD, research fellow

P J JOHNSON, MRCP, senior lecturer in medicine

ROGER WILLIAMS, MD, FRCP, director and consultant physician pancreatic carcinoma ${ }^{8}$; we studied nuclear as well as cytosolic oestrogen binding in six specimens of malignant pancreatic tissue. In view of the possibility that the presence of steroid receptors in malignant pancreas might represent the derepression of fetal genes we also carried out studies with fetal pancreas. Since the specimens might have been contaminated with other competing proteins we estimated both the high-affinity, lowcapacity sex-hormone-binding globulin and the low-affinity, high-capacity human serum albumin, major oestrogen binding proteins.

\section{Patients and methods}

Six specimens of pancreatic carcinoma tissue were obtained, three at laparotomy (two from men aged 69 and 48 years and one from a woman aged 56) and three at necropsy within six hours after death (two from men aged 73 and 78 years and one from a woman aged 78). All specimens were stored in liquid nitrogen and studied within 10 days except the one obtained from the 73-year-old patient at necropsy, which was stored at $-20^{\circ} \mathrm{C}$ for five months. Histological examination confirmed ductular cell carcinoma in all cases.

Pancreatic tissue was obtained from five fetuses (12-14 weeks) aborted by the use of intrauterine prostaglandin and was used as pooled tissue of three and two specimens. Normal pancreas taken at necropsy within five hours after death from three men and one woman dying of unrelated diseases served as control tissue.

PREPARATION OF CYTOSOL AND NUCLEOSOL AND ESTIMATION OF RECEPTOR BINDING

Tissue samples were manipulated below $4 \mathrm{C}$ and homogenised in TED buffer (10 mmol TRIS, $1.5 \mathrm{mmol}$ EDTA, and $1 \mathrm{mmol}$ dithiothreitol/1, pH 7.4) using an Ultra-Turrax before centrifugation at 